\title{
Improve Students' Comprehensive Quality by Six Step Teaching Method
}

\author{
ZhangFei $^{1, a}$ \\ ${ }^{1}$ Engineering Training Center of Shanghai Polytechnic University, Shanghai, China,201209 \\ azhangfei@sspu.edu.cn
}

Keywords: NC machining process; Six step teaching method; Comprehensive quality. Abstract. In order to enhance the students' comprehensive quality, meet the needs of enterprises for talents, improve the employment rate of College students. This paper introduces the application of the six step teaching method in the teaching of numerical control processing technology course, which allows students to participate in the specific teaching process, so as to let the students in the comprehensive ability to get exercise and improve.

\section{Introduction}

Under the new education situation, the demand for the comprehensive quality and innovative ability of the applied talents become higher and higher. The comprehensive quality is the basic condition of the talent innovation ability. The innovation ability is the core competition ability of the talented person. How to cultivate and shape the cultivation of students' comprehensive quality and innovative ability is an important subject in the reform and development of higher education ${ }^{[1]}$. Many training courses of mechanical field are concentrated in the cultivation of skills training, to enable students to master some skills, and ignore the cultivation of students' comprehensive quality and creative ability, such as student information collection, analysis and processing capabilities, and set up an independent work plan ability, communication ability in professional knowledge, practical ability and the team cooperation ability, and ability to work on their own self detection and evaluation etc.. Those abilities are the enterprise qualified personnel should have. To achieve this objective, advanced teaching methods is very important. In this paper, by six step teaching method in the course of NC machining process used to introduce this teaching method, let the students to improve their comprehensive quality and innovative ability in the course of training.

\section{Curriculum objectives}

To train the students' ability of collecting, analyzing and processing the information of the students through the processing technology design and development of the typical project.

According to the formulation of the processing technology to process the product, to test the rationality of the process, and can exercise the students professional knowledge exchange ability, practical ability and team cooperation ability.

To cultivate students' ability of self testing and evaluation through quality inspection and evaluation of their own level.

\section{Instructional design}

\section{Teaching model}

Small class (24 people) teaching mode and group (2 person / group) teaching mode combination. Teaching method

Teaching with the "six step teaching method" . 


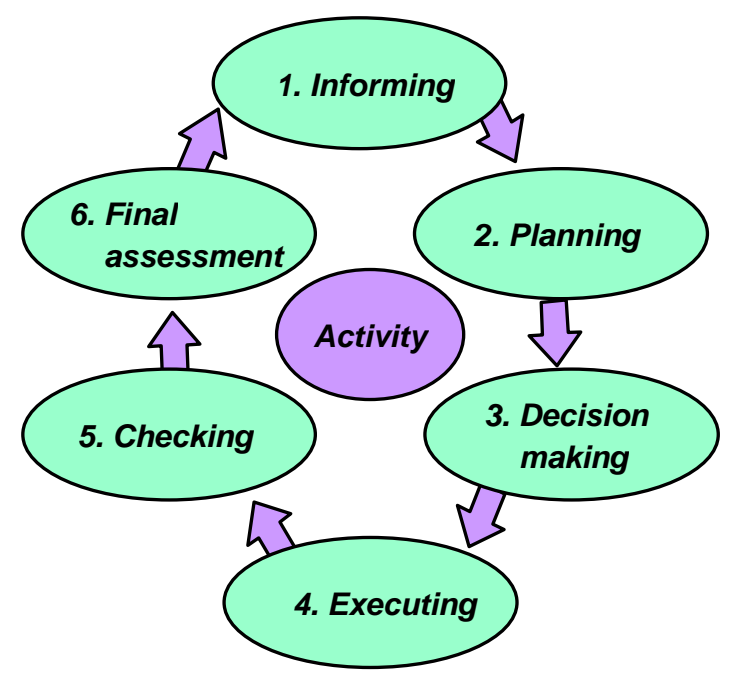

Fig 1. Six step teaching method

\section{Curriculum implementation}

\section{Informing}

Start any activity by considering the information needed, as necessary input, knowledge, procedure, strategies etc.The main task of instructor is to provide some of the necessary professional knowledge, such as processing technology, digital computing and students to do the project there may be some of the knowledge of the blind spot, etc.. This process mainly exercises the ability of students to collect information.

\section{Planning}

Prepare a written work plan with varieties of procedures, working steps, material, equipment, accessories, time frame etc. and define the performance standard. Each of the students develop their own work plan. This process is mainly to exercise the ability of students to coordinate arrangements for work and time planning.

\section{Decision making}

Compare the work plan with regard to the possibly most optimal way (saving of time, saving of efforts, saving of material) in order to perform the activity most effectively and decide about the best final approach.This process fully exercise the professional communication skills of students.

\section{Executing}

Execute the activity in your team according to your plan. The teacher according to the specific situation to do some necessary guidance. At the same time for each student to carry out the process of assessment records. This process mainly tests the students' practical ability and processing skills and teamwork ability.

\section{Checking}

Check the quality not only during executing, but also finally after finishing the task. This process is mainly to exercise the skills of checking.

Final assessment

Evaluate and assess the quality, the entire procedure and the efficiency of your approach in order to consolidate your experience of similar or following tasks. This process is mainly to exercise the ability of student work summary and professional communication ability and the ability to work self assessment.

\section{Curriculum assessment}

Teacher according to the front six teaching process divided into 15 categories were recorded and graded, accounting for the total score of $30 \%$, and then according to the quality of the machined parts 
accounted for $70 \%$ of the total score. Eventually give students a relatively fair, objective and comprehensive assessment results.

\section{Characteristics and innovation}

Take the six step teaching method as the curriculum organization form, organization teaching. Change the original assessment model with the theory of assessment and result assessment. Change to focus on the process of assessment for the evaluation system (through a series of forms), emphasizing the work style and habits of the training.

\section{References}

[1] Yuheng Song. Study On the training mechanism of comprehensive quality and innovative ability of Applied Talents[J].China,2013,(8). 